\title{
Milestones of the History of Neonatal Intensive Care in Korea
}

Jung-Hwan Choi, M.D.

Department of Pediatrics, Seoul National University College of Medicine, Seoul, Korea

\section{한국에서 신생아 집중치료 역사의 이정표}

\section{서울대학교 의과대학 소아과학교실}

최중환

\section{ABSTRACT}

Received: 2 August 2013

Accepted: 9 August 2013

Neonatal intensive care was introduced much later in Korea than in Europe and the United States, where it was introduced during the last decade of the 19th century. During the 1950s-60s, general supportive neonatal care could be provided in nurseries, and during the 1960s-70s, incubator care could be given to preterm infants in premature rooms. In the 1980s, neonatal intensive care could be provided to premature and sick full-term infants in neonatal intensive care units (NICUs) of some major medical centers; the quality of neonatal intensive care improved and the number of NICUs rapidly expanded during the 1990s and 2000s. It can be assumed that the rapid development of neonatal intensive care in Korea may have been induced by the improvement in the Korean socio-economical environment, public demand, numerous study visits and lectures in Korea by distinguished foreign neonatologists, return of native Korean neonatologists trained at famous foreign institutions, and establishment of Korean medical societies (e.g., the Korean Society of Perinatology and the Korean Society of Neonatology). As a result, neonatal and infant mortality rates have dramatically decreased in Korea, especially the mortality rates of low birth weight, very low birth weight, and extremely low birth weight infants. However, despite present and future difficulties in Korea, it is essential to develop and promote the more advanced and institutionalized neonatal intensive care with the set-up of regionalization and transportation system at the perinatal centers in cooperation with primary and secondary hospitals, the government, city, and communities.

Key Words: Neonatal intensive care, Preterm infant, Infant mortality, Transportation

Correspondence to:

Jung-Hwan Choi, M.D. Department of Pediatrics, Seoul National University College of Medicine, 101 Daehak-ro, Jongno-gu, Seoul 110-765, Korea Tel: +82-2-2072-3630, Fax: +82-2-743-3455,

E-mail: neona@snu.ac.kr
Copyright(c)

By Korean Society of Neonatology.

All right reserved. 
서론

대한신생아학회 창설 20 주년에 즈음하여 외국과 국내 신생아 학 발전의 이모저모를 살펴보고 지난 20년 간 우리나라 신생아 집 중치료의 역사를 되돌아 보고자 '한국에서의 신생아 집중치료의 역사'에 대해서 저술하기로 결정하였다.

우리나라에서의 신생아 집중치료의 발달을 기술하려면 먼저 서양에서의 신생아 집중치료의 발달에 대해 알아보고 비교해 보 는 것이 필요하다. 서양에서 18 세기 전에는 여아나 선천성 기형을 가진 아기, 또는 미숙아들을 유기하여 죽게 내버려 두는 것이 허 용되기도 하였다. 이 당시 수녀원이나 아동 치료구호소 등에서 아 기를 데려가서 정성과 지지적 치료(supportive care)로 살리려고 애를 썼으나 그 생존율은 미약하였다 (Table 1). 서양에서는 19세 기 말부터 신생아 치료에 관심을 갖기 시작하였고 1930년경부터 신생아 집중치료가 발달되어 왔으나, 우리나라에서는 몇 병원을 제외하고는 1950년 한국전쟁 이후부터 서서히 신생아 치료에 관 심을 갖게 되었고, 1970 년 이후 여러 요인에 의해 빠르게 신생아 집중치료가 도입되고 발달되어 왔다.

이에 본 저자는 2007 년 5 월 23 일에 본원 임상의학연구소 대강 당에서 새로 개보수 및 확장된 신생아 집중치료실(NICU) 설립 1 주년을 기념하여 Lawrence M. Gartner 명예교수(미국 Chicago 의대), Kwang-sun Lee 교수(미국 Chicago 의대), Christian P. Speer 교수(독일 W rzburg 의대), Victor Yu 교수(호주 Monash 의 대)와 Hiroshi Nishida 교수(일본 동경여의대) 등을 초청하여 열 렸던 'The Seoul Neonatology Symposium: Historical Overview of Neonatal Intensive Care in Europe, the U.S., Australia, Japan, and Korea'에서 발표되고 논의되었던 내용을 중심으로 ${ }^{2}$ 문헌을 조사하여 역사적 고찰을 통해 신생아 집중치료 발달이 서양과 비 교하여 우리나라에서 어떻게 발달되어 왔고, 현시점에서의 문제점 은 무엇이며, 향후 그 해결방안은 무엇인지를 알아보고자 하였다.

\section{본론}

\section{1. 신생아 집중치료 발달의 역사적 고찰 ${ }^{1-3)}$}

1881년 인큐베이터를 최초로 만든 프랑스 산부인과 의사 St phane Tarnier 의 제자인 Pierre Budin은 그의 제자인 Martin Couney와 함께 1800년대 말부터 1900년대 초에 베를린, 런던이나 뉴욕에서 개최된 만국박람회(expo)에 건물을 짓고 아기를 넣은 인 큐베이터를 설치하고 일반인들에게 전시하여 생긴 이익금으로 더 많은 인큐베이터를 구입하여 미숙아나 선천성 기형아를 치료 하여 이 아기들에 대한 비관적 태도를 낙관적 태도로 바꾸어 놓았 다. 이 때 1891-1894년에 Alexandre Lion에 의해서 개발된 인큐베 이터가사용되었다.

1930년경에 이르러 시카고 산과병원(Chicago Lying-in Hospital; 후에 시카고대학병원이 됨)의 Joseph DeLee와 시카고 Sarrah Moris Hospital(후에 Michael Reese Hospital로 바뀜)의 Julius Hess 는 병원 내에 미숙아실을 마련하고 인큐베이터를 설치하여 병원 내에서 본격적으로 신생아 집중치료를 시작하였다.

William Dewee와 같은 생리학자가 지속성 태아 순환(persistent fetal circulation, $\mathrm{PFC}$ )이나 태반 기능 등에 대해서 연구를 하였고, Virginia Apgar는 출생 후 아기의 건강 상태를 점검하는 Apgar 점

Table 1. The Milestones in the History of the Development of Neonatal Intensive Care

\begin{tabular}{ll}
\hline Foundling house & \multicolumn{1}{c}{ Natural selection } \\
\hline Pierre Budin, Alexandre Lion \& Martin Couney & $\begin{array}{l}\text { Pioneer of care of premature babies in incubator } \\
\text { Change the pessimistic attitudes to the optimistic attitudes }\end{array}$ \\
Julius H. Hess \& Joseph DeLee & Nursery care of premature babies in the hospital \\
William P. Dewees & Perinatal physiology (PFC, placental function) \\
Virginia A. Apgar & Evaluation of well-being of NB infant \\
Louis Gluck & Inverted the concept of neonatal intensive care \\
& Build the first NICU at Yale New Haven Hospital \\
& Discovered the biochemical basis for RDS and the amniotic fluid test for surfactant activity \\
& (L/S ratio) \\
William A. Silverman & Therapeutic trial - (sulfonamide; kernicterus) \\
& Performed first neonatal randomised controlled clinical trials for ACTH treatment of ROP \\
Mary E. Avery & RDS (HMD) - Ex; surfactant deficiency \\
Lawrence M. Gartner \& Kwang-sun Lee & Physiologic jaundice - delayed maturation of UDP glucuronyl transferase \\
Tetsuro Fujiwara & RDS (HMD) - Treatment with artificial surfactant
\end{tabular}

Abbreviations: PFC, persistent fetal circulation; NB, newborn; NICU, neonatal intensive care unit; RDS, respiratory distress syndrome; L/S ratio, lecithin/sphingomyelin ratio; ACTH, adrenocorticotropic hormone; ROP, retinopathy of prematurity; HMD, hyaline membrane disease. 
수를 만들었으며, William Silverman은 미숙아 망막증에 대한 부 신 피질 자극 호르몬의 임상시험을 처음으로 시행하였고 미숙아 에게 sulfonamide로 치료시 핵황달(kernictrus)이 생기는 것을 보 고하였다.

Louis Gluck는 1960년에 신생아 집중치료라는 개념을 처음 도 입하였고 Yale의대 New Haven 병원에 미국 최초의 NICU를 설립 하였으며, 미숙아 호흡곤란증의 생화학적 근거와 폐 표면활성제
에 대한 양수액검사, 즉 Lecithin/sphingomyelin 비(L/S ratio)에 대 해 발표하였다.

1957년 Mary E. Avery는 미숙아 호흡곤란증후군(hyaline membrane disease, $\mathrm{HMD}=$ respiratory distress syndrome, RDS)의 원인 이 폐 표면활성제(surfactant)의 결핍 때문이라는 것을 보고하였 고, 여러 학자들의 노력과 Tetsuro Fujiwara에 의해 인공 폐 표면 활성제(artificial lung surfactant)가 만들어져 1980년 미숙아에게

Table 2. Diagnostic \& Therapeutic Advances in Neonatology in Europe \& the U.S.

Infection control of nursery
Care of premature babies ;
$\begin{aligned} & \text { thesuscitation } \\ & \text { thermoregulation }\end{aligned}$
simple \& exchange transfusion
supportive care of respiratory distress

1960 s

Electronic monitor - blood gases

Feeding by nasogastric tube

Laboratory equipment

Antibiotics

Phototherapy

$1970 \mathrm{~s}$

Umbilical artery catheter and umbilical vein catheter

Nutritional support by transpyloric feeding \& total parenteral nutrition

Neonatal surgery (open heart surgery for congenital heart disease)

Mechanical ventilator care in respiratory distress

$1980 \mathrm{~s}$

Development of diagnostic radiology (CT, USG, MRI)

Transcutaneous electrodes ; TcPO2, TcPCO2

High frequency ventilation

Indomethacin therapy for closure of patent ductus arteriosus

Oxygen saturation monitoring by pulse oximetry ( $\mathrm{SpO} 2)$

Artificial surfactant replacement therapy

Eextracorporeal membrane oxygenation

Cryotherapy for retinopathy of prematurity

$1990 s$

Intravenous immunoglobulin therapy in sepsis

G-CSF of GM-CSF for neutropenia

Magnetic resonance spectroscopy, Near infrared spectroscopy

Laser photocoagulation therapy for ROP

Transthoracic ligation of PDA

Liquid ventilation in respiratory failure

Capnometer (EtCO2)

New mode mechanical ventilation; SIMV, PTV, HFO

Inhaled NO therapy in PPHN

Photocoagulation therapy for ROP

Prenatal \& postnatal zidovudine for prevention for human AIDS

2000s

Positron emission tomography

Recombinant human surfactant for respiratory distress syndrome

New mode mechanical ventilation ; NAVA, PAV, etc

Steroid therapy, Vitamin A, stem cell therapy for bronchopulmonary dysplasia

rhEPO, hypothermia, stem cell therapy for HIE

Abbreviations: CT, computer tomography; USG, ultrasonography; MRI, magnetic resonance imaging; G-CSF, granulocyte colony-stimulating factor; GM-CSF, granulocyte-macrophage colony-stimulating factor; SIMV, synchromized intermittent mandatory ventilation; PTV, patient triggered ventilation; HFOV, high frequency oscillation; PPHN, persistent pulmonary hypertension of the newborn; AIDS, acquired immune deficiency syndrome; NAVA, neurally adjusted ventilatory assist; PAV, proportionate assist ventilation; rhEPO, recombinant human erythropoietin. 
처음으로 투여하여 성공적인 결과를 얻게 되었다.

Lawrence Gartner와 Kwang-sun Lee는 신생아 생리적 황달 의 원인이 간에서의 UDP-glucuronyl transferase의 지연 성숙 (delayed maturation)에 의한 것이라는 것을 침판지 실험을 통해 밝혀내는 등 많은 신생아학 전공 학자들에 의해 신생아 집중치료 가 지속적으로 발달하여 지금에 이르게 되었다 (Table 1).

\section{2. 신생아학에서의 진단 및 치료의 발달}

서양에서의 년대별 신생아 질환에 대한 진단 및 치료의 발달은 Table 2 에서와 같다 ${ }^{1-3)}$. 1930 년대부터 병원 내에서의 신생아 집중 치료가 시작되기는 했으나 1950 년대에 들어서야 본격적인 신생아 집중치료가 발달하게 되었다.

즉 1950 년대에는 신생아실에서의 감염 조절과 소생술, 미숙 아에 대한 온도조절, 단순 및 교환 수혈, 호흡곤란에 대한 지지 요법(supportive care) 등이 시행되었고, 1960년대에는 혈액가스 분석기가 만들어져 호흡곤란 신생아의 산염기 상태를 알 수 있 게 되었고, 비위관(nasogastric tube)을 통한 경관영양요법, 검사 실 기구의 발달, 신생아 감염에 대한 항생제의 출현, 신생아 황 달의 치료로 광선요법 등이 도입되었다. 1970년대에는 제 대동 맥관(umbilical artery catheter, UAC) 및 제대정맥관(umbilical vein catheter, UVC) 삽입시술의 시행, 경유문 영양(transpyloric feeding) 및 총정맥영양(total parenteral nutrition, TPN)에 의 한 영양 보조, 아주 소량의 채취된 피를 이용한 미세화학적 검사 (microchemisrty test), 선천성 심장병에 대한 개흥술(open heart surgery) 등의 신생아 수술 시행, 신생아 호흡곤란증(RDS)에 대한 기계적 환기요법(mechanical ventilator care) 등이 시행되었다.

1980년대에는 뇌초음파(USG), 컴퓨터단층촬영(CT scan), 자기 공명영상(MRI) 등의 진단 영상의학적 발달로 신생아 질환에 대 한 비약적인 발전이 있었고, 혈액을 채취하여 검사하는 혈액가스 분석기 대신에 혈액 채취가 필요 없는 경피산소분압 $\left(\mathrm{TcPO}_{2}\right)$ 과 경 피이산화탄소분압 $\left(\mathrm{TcPCO}_{2}\right)$ 모니터와 산소포화도 측정기(pulse oximetry), 고빈도환기요법, 인공 폐 표면활성제, 동맥관개존증 (patent ductus arteriosus, PDA)의 약물요법(indomethacin), 체외 막 산소화(extracorporeal membrane oxygenation, ECMO) 등의 발 달과 미숙아 망막증의 냉동요법(cryotherapy)이 시작되었다.

1990년대에는 자기공명분광(magnetic resonance spectroscopy) 와 근적외선분광분석기(near-infrared spectroscopy)에 의한 뇌 의 기능 및 산소화 정도의 평가가 가능해 졌고, 탄산가스측정기 (capnometer; $\mathrm{EtCO}_{2}$ )에 의한 지속적인 측정이 가능해 졌으며, 신 생아 패혈증에 대한 IVIG 요법, 동맥관개존증(PDA)에 대한 수술 적 결찰, 새로운 인공환기요법의 개발, 지속적 신생아 폐 고혈압 증(persistent pulmonary hypertension of newborn, PPHN)에 대 한 일산화질소 가스(inhaled nitro oxide, iNO) 요법 및 sildenafil
등의 약물요법, 미숙아 망막증의 광응고요법(photocoagulation therapy), 후천성 면역 결핍 증후군(acquired immune deficiency syndrome)의 주산기 감염의 예방을 위한 zidobudine 치료요법 등 이 가능해 졌다.

2000년대에 이르러는 양전자 방출 단층 촬영(PET) 의 출현으 로 여러 기관의 기능적 진단이 가능해 졌고, 미숙아 호흡곤란증의 치료로서 재조합 폐 표면활성제(recombinant human surfactant, rhS)의 생산, NAVA (neurally adjusted ventilatory assist), PAV (proportionate assist ventilation)와 같은 새로운 인공환기요법의 개발, 기관지 폐 이형성증 $(\mathrm{BPD})$ 에 대한 치료로 비타민 A 외에 줄 기세포치료(stem cell therapy)의 실험적 연구, 저산소성-허혈성 뇌병증(HIE)에 대한 뇌보호요법으로 rhEPO (recombinant human erythropoietin) 투여, 저체온요법(hypothermia), 그리고 줄기세포 치료 및 aEEG(amplitude integrated electroencephalography)를 이 용한 진단법 등이 발전되어 왔다.

우리나라에서는 서양이나 일본보다 20-30년 정도 늦게 신생아 질환에 대한 진단 및 치료가 발달하기 시작했는데 연대별 발달 상 황은 Table 3 에서와 같다 ${ }^{2,45}$. 몇 병원을 제외하고 대부분의 병원 에서 한국전쟁이 끝난 후인 1950년대와 1960년대에는 신생아실 에서 감염에 대한 항생제 치료, 산소요법, 교환수혈 등의 지지요

Table 3. Diagnostic \& Therapeutic Advances in Neonatology in Korea

1950s-60s Nursery, antibiotics, oxygen, exchange transfusion

1960s-70s Premature room, incubators

1980s NICU, infant warmer, MV care, TPN, brain USG, CT, MRI

Cryotherapy for ROP

1990s Artificial surfactant therapy, HFOV, liquid ventilation, steroid therapy in CLD, fluid restriction, SIMV with PTV

Indomethacin therapy for PDA Photocoagulation therapy for ROP

2000s N-CPAP, inhaled NO therapy, new mode of MV, head cooling

Transthoracic ligation for PDA

Ibuprofen therapy for PDA

Caffeine therapy for apnea

2007 Neonatology sub-board certification system

$2013 \quad$ Korean Neonatal Network (KNN)

Abbreviations: NICU, neonatal intensive care unit; MV, mechanical ventilation; TPN, total parenteral nutrition; USG, ultrasonography; CT, computer tomography; MRI, magnetic resonance imaging; ROP, retinopathy of prematurity; HFOV, high frequency oscillation ventilation; CLD, chronic lung disease; SIMV, synchronized intermittent mechanical ventilation; PTV, patient triggered ventilation; PDA, patent ductus arteriosus; N-CPAP, nasal continuous positive airway pressure. 
법(supportive care)이 시작되었고, 의과대학에 신생아학 강좌가 개설되기 시작했으며, 1960년대와 1970년대에는 미숙아실이 생 기기 시작하고 보육기가 설치되었다. (예, 1970년 소화아동병원에 보육기 50대 설치), 1980년대부터 각 병원에 신생아 집중치료실 (NICU)이 생기기 시작하고 영아 온열기(infant warmer), 환아감시 장치(patient' monitor), 인공환기기, 총정맥영양(TPN), 미숙아 망 막증(ROP)에 대한 냉동요법(cryotherapy) 등이 시행되었으며, 뇌 초음파 (USG), 컴퓨터단층촬영(CT scan), 자기공명영상(MRI) 등 에 의한 첨단 장비들에 의한 진단도 가능하게 되었다. 1990 년대에 는 인공 폐 표면활성제 치료, 동맥관개존증의 indomethacin 치료, 고빈도환기요법(high frequency oscillatory ventilation, HFOV), 기관지 폐 이형성증의 steroid 치료, PTV (patient triggered ventilation)를 이용한 인공환기요법, 미숙아 망막증에 대한 광응 고요법 등이 시행되었으며, 2000년대에 이르러서는 n-CPAP, 신 생아 지속성 폐고혈압증 (PPHN)에 대한 iNO 치료 요법, NAVA, $\mathrm{PAV}$ 등과 같은 새로운 인공환기요법, 저산소성 허혈성 뇌병증 (HIE)의 진단에 $\mathrm{aEEG}$ 이용과 두부냉각법(head cooling) 등 저체온 요법(hypothermia) 및 stem cell therpy 등의 뇌보호 치료법, 동맥 관개존증 $(\mathrm{PDA})$ 에 대한 수술적 결찰요법 및 ibuprofen 치료, 미숙 아 무호흡에 대한 caffein 치료법들이 시행되었다. 특히 2007년에 는 대한신생아학회 주관으로 신생아학 분과전문의 제도가 처음 으로 시작되었고, 2013년에는 대한신생아학회 특별위원회에서 한국 신생아 네트워크(Korea Neonatal Network, KNN)이 구축되 었다 ${ }^{6)}$

\section{3. 신생아 집중치료실(Neonatal intensive care unit, NICU)의 설립}

서양에서 산생아 집중치료실(NICU)은 산과학, 소아과학, 생리 학을 기반으로 심장학, 신경학, 영상의학, 외과학, 마취과학, 안과 학 등 여러 분야의 학문들이 협조하여 이루어졌는데, 더불어 치료

\begin{tabular}{|c|c|c|}
\hline \begin{tabular}{l|l} 
Obstetrics & \\
Pediatrics \\
Physiology
\end{tabular} & \begin{tabular}{|l} 
Intensive \\
Care \\
Nursery
\end{tabular} & $\begin{array}{l}\text { Therapeutic environment } \\
\text { Equipment } \\
\text { Multidisciplinery team with a } \\
\text { relevant scientific knowledge } \\
\text { Regionalization \& Transportation } \\
\text { Moral issues } \\
\text { Cost-benefit measures } \\
\text { After-care education }\end{array}$ \\
\hline $\begin{array}{l}\text { Obstetrics } \\
\text { Neonatology } \\
\text { Cardiology } \\
\text { Neurology } \\
\text { Radiology } \\
\text { Surgery } \\
\text { Anesthesiology }\end{array}$ & & $\begin{array}{l}\text { Hospital administration } \\
\text { Legislator } \\
\text { Congress \& courts } \\
\text { Malpractice lawyer } \\
\text { Ethicists } \\
\text { Insurance company } \\
\text { Social worker \& psychotherapist }\end{array}$ \\
\hline
\end{tabular}

Fig. 1. Establishment of neonatal intensive care units for providing neonatal intensive care.
환경(공간 등), 진단 및 치료 장비, 훈련이 잘 되어 있는 인력, 신생 아 네트워크 결성, 지역화 및 환아 이송(regionalization \& transportation), 도덕적인 문제, 비용-이익의 측정, 추적관찰에 대한 교 육 등을 기반으로 한 병원 행정, 법률제정자, 국회의원, 의료분쟁 변호사(malpractice lawyer), 윤리학자, 보험회사, 사회사업가, 정 신분석자 등의 협조에 의해 만들어 졌다고 할 수 있다 ${ }^{1-3)}$ (Fig. 1).

우리나라의 신생아 집중치료실도 서양에 비해 많이 부족한 면 이 있기는 했지만 비슷한 과정을 거쳐 각 병원에서 만들어지게 되 었다 ${ }^{2,4-6)}$.

\section{4. 신생아 관련 학회|대한주산의학회, 대한신생아학연구회, 대 한신생아학회)의 설립과 발전}

1) 대한주산의학회(The Korean Society of Perinatology) $)^{2,7)}$

대한주산의학회는 산부인과의 강신명, 노경병, 송명도 선생 님들이 주축이 되어 1986년 6월 30일에 조선호텔에서 창립총회 를 개최하였으며 노경병 선생님이 초대회장으로 선출되었다. 소 아과에서는 윤종구, 조성훈, 한동관 선생님들을 주축으로 전정 식, 이철, 최중환 등이 참여하였다. 1986년 10월 10 일 제 1 차 추계 학술대회가 시작된 후 2012 년 제 25 차 추계학술대회까지 산모와 아기와 관련된 많은 연제의 심포지움과 일반연제 및 포스터 발표 가 시행되었으며, 1994 년 제 1 차 춘계연수강좌가 시작된 이후 2013 년 제 18 차 춘계연수강좌까지 많은 주제에 대한 교육강좌가 발표 되었다. 1990년부터는 대한주산의학회지(The Korean Journal of Perinatology)가 간행되기 시작하여 2013년 현재까지 제21권 3호 가 출간되었다. 제 2 대 김승욱, 제 3 대 이재현, 제 4 대 배도환, 제 5 대 이현영 회장까지는 산부인과에서 회장직을 맡아 왔으나 1996년 제6대 한동관 회장이 소아과에서 취임한 이후에는 산부인과와 소아과에서 2 년마다 번갈아 가면서 회장직을 수행하여 왔는데, 그 후 소아과에서는 2000년 제8대 피수영 회장, 2004년 제10대 문 수지 회장, 2008년 제 12 대 유병훈 회장에 이어 2012년부터 제 14 대 김민희 회장이 학회를 성공적으로 이끌고 있다. 특히 1998년에 '아시아 대양주 주산의학회'가 서울 인터콘티넨탈호텔에서 소아 과 한동관 회장겸 공동조직위원장의 주도하에 많은 국외 회원과 국내 회원들의 참여로 성황리에 성공적으로 치루어진 것은 높게 평가되어야 할 것이다. 현재 대한주산의학회의 쟁점인 '고위험 산 모 신생아 통합치료센터 설립을 위한 공청회'가 2013년 7월 20일 에 개최되었다.

2) 대한신생아학연구회(The Korean Society of Neonatal Research $)^{2,6)}$

소아과 윤종구, 조성훈, 한동관 선생님들이 주축이 되어 대한신 생아학연구회 창립 모임을 갖기로 결정하고 1986년 11월 28일 서 울대학교 어린이병원에서 '뇌실내-뇌실주위 출혈이 있는 미숙아 2례'에 대한 증례 발표 및 주제 발표회를 가진 후 교수식당에서 창 
립총회를 갖고 회장 윤종구, 부회장 조성훈, 총무 최중환을 선출 하고 각 병원이 주관하는 신생아학 집담회를 돌아가면서 하기로 결정한 이후 1993년 9월까지 7년간 36회를 지속하며 대한신생아 학회의 창립의 초석을 마련하였다. 그동안 윤종구 회장과 조성훈 부회장은 그대로 유임되었으나, 총무는 1987년에 전정식, 1989년 에 이철, 1990년에 문수지, 1993년에 배종우로 바뀌어 가며 대한 신생아학연구회가 운영되었다. 제 1 회부터 제 36 회까지의 신생아 학 집담회의 연제 및 주관병원은 Table 4에서와 같다.
3) 대한신생아학회 (The Korean Society of Neonatology) $)^{2,6,8)}$ 1986년 11월부터 1993년 9월까지 7년간의 대한신생아학연구회 에서의 신생아학 집담회를 통해 초석을 다지고 창립 준비위원회 의 준비활동을 거쳐 드디어 1993년 10 월 23 일 서울쉐라톤워커힐 호텔에서 대한신생아학회 창립총회가 개최되었다. 많은 회원들 이 참석한 이 자리에서 초대 회장 윤종구, 부회장 조성훈, 한동관, 감사 나창수, 금동혁, 총무위원장 배종우가 선출되었으며, 다음 해인 1994년 5월 14 일 부산태평양호텔에서 열린 제1차 춘계학술 대회에서 '신생아 인공환기요법'이라는 주제로, 10 월 22 일 서울쉐 라톤워커힐호텔에서 열린 제1차 추계학술대회에서 '이상적인 신

Table 4. List of Meetings of the Korean Society of Neonatal Research (1986-1993)

\begin{tabular}{|c|c|c|c|}
\hline Date & Host institute & Topics & Remarks \\
\hline 1st 986.11.28 & SNU College of Medicine SNUH & $\begin{array}{l}\text { Two cases of preterm infants with intraventricular- } \\
\text { periventricular hemorrhage }\end{array}$ & $\begin{array}{l}\text { Presiden; Chong Ku Yoon } \\
\text { Vice president; Sung Hoon Cho } \\
\text { SG; Jung-Hwan Choi }\end{array}$ \\
\hline 2nd 1987.2.26 & $\begin{array}{l}\text { CU College of Medicine } \\
\text { St. Mary's Hosp. }\end{array}$ & $\begin{array}{l}\text { A case of adrenogenital syndrome } \\
\text { Effect of phototherapy on gut transit time in neonatal } \\
\text { hyperbilirubinemia }\end{array}$ & \\
\hline 3rd 1987.3.26 & Sowha Children's Hosp. & Two cases of necrotizing enterocolitis in neonate & \\
\hline 4th 1987.4.30 & $\begin{array}{l}\text { YU College of Medicine } \\
\text { Severance Hosp. }\end{array}$ & $\begin{array}{l}\text { A case of neonatal sepsis and disseminated } \\
\text { intravascular coagulation }\end{array}$ & \\
\hline 5th 1987.5.28 & KHU College of Medicine KHUMC & $\begin{array}{l}\text { Hemolytic anemia caused by minor blood group } \\
\text { incompatibility }\end{array}$ & \\
\hline 6th 1987.6 .18 & HU College of Medicine HUMC & $\begin{array}{l}\text { Two cases of persistent pulmonary hypertension of } \\
\text { neonate }\end{array}$ & \\
\hline 7th 1987.9 .24 & SCHU College of Medicine SCHUH & $\begin{array}{l}\text { A case of citrullinemia, } \\
\text { A case of pancreatic islet cell adenoma, } \\
\text { A case of short bowel syndrome, } \\
\text { A case of peptic ulcer in newborn infant }\end{array}$ & \\
\hline 8th 1987.11.19 & CAU College of Medicine CAUYH & $\begin{array}{l}\text { A case of idiopathic neonatal hepatitis, } \\
\text { A case of spontaneous neonatal gastric perforation }\end{array}$ & SG : Chung Sik Chun \\
\hline 9th 1988.4 .28 & EWU College of Medicine EWUDH & $\begin{array}{l}\text { Transient myeloproliferative disorder associated with } \\
\text { Down syndrome }\end{array}$ & \\
\hline 10th 1988.5. & Cheil General Hosp. & $\begin{array}{l}\text { A case of female pseudohermaphroditism due to } \\
\text { maternal Krukenberg tumor } \\
\text { The early anemia of the premature infant and vit. E } \\
\text { supplementation }\end{array}$ & \\
\hline 11th 1988.6.23 & SCHU College of Medicine SCHUH & $\begin{array}{l}\text { Retinopathy of prematurity } \\
\text { Cerebral blood velocity, ICP monitoring and } \\
\text { intracranial bleeding of prematurity }\end{array}$ & \\
\hline 12th 1988.11 .24 & HU College of Medicine HSHH & $\begin{array}{l}\text { A case of Potter syndrome } \\
\text { A case of congenital factor XIII deficiency }\end{array}$ & \\
\hline 13th 1989.3.30 & YU College of Medicine YSH & $\begin{array}{l}\text { Fluid and electrolyte management of premature } \\
\text { infant }\end{array}$ & SG : Chul Lee \\
\hline 14th 1989.5.25 & $\begin{array}{l}\text { YU College of Medicine Severance } \\
\text { Hosp. }\end{array}$ & $\begin{array}{l}\text { Exogenous surfactant replacement therapy of hyaline } \\
\text { membrane disease }\end{array}$ & \\
\hline 15th 1989.6.22 & Bangjigo Hosp. & Retinopathy of prematurity & \\
\hline
\end{tabular}


Table 4. List of Meetings of the Korean Society of Neonatal Research (1986-1993) (Contiuned)

\begin{tabular}{|c|c|c|c|}
\hline Date & Host institute & Topics & Remarks \\
\hline 16th 1989.9.28 & SNU College of Medicine SNUH & $\begin{array}{l}\text { Two cases of BPD } \\
\text { A case of esophageal perforation }\end{array}$ & \\
\hline 17th 1989.11 .30 & Seoul Red Cross Hosp. & A case of necrotizing enterocolitis in term infant & \\
\hline 18th 1990.3.29 & $\begin{array}{l}\text { CU College of Medicine } \\
\text { St. Mary's Hosp. }\end{array}$ & $\begin{array}{l}\text { A case of hydrometrocolpos, } \\
\text { Respiratory care in NICU }\end{array}$ & SG : Soo-Ji Moon \\
\hline 19th 1990.5.31 & $\begin{array}{l}\text { IU College of Medicine } \\
\text { Sanggye Paik Hosp. }\end{array}$ & Aberrant right subclavian artery with laryngomalacia & \\
\hline 20th 1990.6.28 & Hotel the Shilla & $\begin{array}{l}\text { Stable microbubble test for early detection of RDS } \\
\text { APR-score in neonatal Infection }\end{array}$ & \\
\hline 21st 1990.11.30 & HU College of Medicine HUMC & Two cases of cytomegalovirus infection & \\
\hline 22nd 1991.3.28 & UU College of Medicine SAMC & Two cases of meconium peritonitis & \\
\hline 23th 1991.4.25 & EWU College of Medicine EWUDH & Neonatal systemic candidiasis & \\
\hline 24th 1991.5. & Hanil Hosp. & $\begin{array}{l}\text { Neonatal tetanus } \\
\text { Ventriculitis and brain necrosis in meningitis }\end{array}$ & \\
\hline 25th 1991.6. & Sowha Children's Hosp. & Hypoxic ischemic enceppalopathy (HIE) & \\
\hline 26th 1991.10.31 & Eulji Hosp. & Surgical conditions in neonates & \\
\hline 27th 1991.11.28 & CAU College of Medicine CAUYH & Two cases of T-E fistula & \\
\hline 28th 1992.4.30 & SNU College of Medicine SNUH & $\begin{array}{l}\text { Principle and practices of newborn genetic disease } \\
\text { screening including PKU screening }\end{array}$ & \\
\hline 29th 1992.6.4 & Cheil General Hosp. & Surfactant therapy in 4 cases of HMD & \\
\hline 30th 1992.7.2 & SCHU College of Medicine SCHUH & $\begin{array}{l}\text { A case of urea cycle disorder, } \\
\text { A case maple syrup urine disease }\end{array}$ & \\
\hline 31st 1992.11.5 & $\begin{array}{l}\text { YU College of Medicine Renaissance } \\
\text { Seoul Hotel }\end{array}$ & Overview of Exosurf Trials-OSIRIS & \\
\hline 32nd 1993.3.25 & HU College of Medicine HUMC & Methemoglobinemia & SG : Chong Woo Bae \\
\hline 33th 1993.4.29 & Sahmyook Medical Center & $\begin{array}{l}\text { Benefits of breast milk } \\
\text { Breast milk bank }\end{array}$ & \\
\hline 34th 1993.6.3 & YU College of Medicine YSH & Intraventricular hemorrhage, periventricular leukomalacia & \\
\hline 35th 1993.6.24 & Renaissance Seoul Hotel & Follow up of high risk infant & \\
\hline 36th 1993.9.23 & National Medical Center & Erythropoietin treatment in preterm infant & \\
\hline
\end{tabular}

Abbreviations: SNU, Seoul National University; SNUH, Seoul National University Hospital; SG, Secretary General; CU, Catholic University; YU, Yonsei University; KHU, Kyung Hee Univeristy; KHUMC, Kyung Hee Univeristy Medical Center; HU, Hanyang University; HUMC, Hanyang University Medical center; SCHU, Soon Chun Hyang University; SCHUH, Soon Chun Hyang University Hospital; CAU, Chung Ang University; CAUYH, Chung Ang University Yongsan Hospital; EWU, Ewha Womans Univeristy; EWUDH, Ewha Womans Univeristy Dongdaemun Hospital; HU, Hallym University; HSHH, Hangang Sacred Heart Hospital; YSH, Youngdong Severance Hospital; IU, Inje University; UU, Ulsan University; SAMC, Seoul Asan Medical Center.

생아 집중치료실'이라는 주제로 심포지움이 개최된 이래 2013년 4 월 26일 부여롯데리조트에서 제20차 춘계학술대회에서 'Korean Neonatal Network: Raze the old to raise the new'라는 주제의 심 포지움이 개최되기까지 20년간 춘계 및 추계 학술대회가 성황리 에 성공적으로 개최되었다. 지난 20 년간의 춘, 추계학술대회의 개 최 일시, 장소, 심포지움 주제, 초청외국연자, 역대 임원은 Table 5 에서와 같다. 초대 및 2 대 회장 윤종구, 총무 배종우에 이어 3 대 회 장 조성훈, 총무 배종우, 4 대 회장 한동관, 총무 김기수, 5 대 회장 피수영, 총무 김기수, 6 대 회장 문수지, 총무 김창렬, 7 대 회장 전
정식, 총무 김병일, 8 대 회장 이 철, 총무 박문성, 9 대 회장 최중환, 총무 김한석, 그리고 2011년 10월부터 현재까지 10대 회장 배종우, 총무 김한석이 학회를 성공적으로 운영하여 지금에 이르게 될 수 있었던 것은 모든 회원의 참여와 협조에 의한 것이었다.

특히 2003년 9월에는 '창립 10주년 기념 국제 신생아학 심포지 움'이 서울쉐라톤워커힐호텔에서 독일 Würzburg의대의 Speer 교수, 스위스 제네바의대의 Hüppi 교수, 일본 나고야시립의대의 Togari 교수, 호주 Royal Women's Hospital의 Morley 교수, 중국 상 하이 Fudan의대의 Bo Sun 교수 5 명의 외국 초청연자들과 김기수, 
Table 5. List of the Annual Meetings of the Korean Society of Neonatology (1993-2013)

\begin{tabular}{|c|c|c|c|c|}
\hline Year & Meeting & Date & Location & Topics / Invited Speakers \\
\hline 1993 & $\begin{array}{r}\text { Inaugural } \\
\text { General } \\
\text { Meeting }\end{array}$ & 10.23 & Sheraton Walkerhill Hotel & $\begin{array}{l}\text { Report by Founded committee for the Korean Society of Neonatology } \\
1^{\text {st }} \text { President : Chong Ku Yun }\end{array}$ \\
\hline 1994 & $\begin{array}{l}\text { Spring } \\
\text { Autumn }\end{array}$ & $\begin{array}{l}5.14 \\
10.22\end{array}$ & $\begin{array}{l}\text { Taepyoungyang Hotel Busan } \\
\text { Sheraton Walkerhill Hotel }\end{array}$ & $\begin{array}{l}\text { Mechanical ventilator in neonate/Victor Yu, Haruo Maeta } \\
\text { Ideal neonatal intensive care unit/Jing Ja Yoon, WH Yoo }\end{array}$ \\
\hline 1995 & $\begin{array}{l}\text { Spring } \\
\text { Autumn }\end{array}$ & $\begin{array}{l}5.12 \\
10.28\end{array}$ & $\begin{array}{l}\text { Shin Yang Park Hotel Kwangju } \\
\text { Sheraton Walkerhill Hotel }\end{array}$ & $\begin{array}{l}\text { Fluid therapy in neonate/Edward Bell } \\
\text { Regionalization and transport in neonatal care/Kwang-sun Lee, Sechin Cho } \\
2^{\text {nd }} \text { President : Chong Ku Yun }\end{array}$ \\
\hline 1996 & $\begin{array}{l}\text { Spring } \\
\text { Autumn }\end{array}$ & $\begin{array}{l}5.17 \\
10.19\end{array}$ & $\begin{array}{l}\text { Grand Daegu Hotel } \\
\text { Sheraton Walkerhill Hotel }\end{array}$ & $\begin{array}{l}\text { Nursing neonate / Clair, Blackburn } \\
\text { Blood disease in newborns / EL Grauel }\end{array}$ \\
\hline 1997 & $\begin{array}{l}\text { Spring } \\
\text { Autumn }\end{array}$ & $\begin{array}{l}5.16 \\
10.18\end{array}$ & $\begin{array}{l}\text { Hotel Lotte Daedeok } \\
\text { Sheraton Walkerhill Hotel }\end{array}$ & $\begin{array}{l}\text { Neonatal RDS and surfactant / Fujiwara T, Chida S, Shimada S } \\
\text { Nutrition and metabolisms in preterm infants/Reginald Tsang } \\
3^{\text {rd }} \text { President : Sung Hoon Cho }\end{array}$ \\
\hline 1998 & $\begin{array}{l}\text { Spring } \\
\text { Autumn }\end{array}$ & $\begin{array}{l}4.3 \\
10.17\end{array}$ & $\begin{array}{l}\text { Sheraton Walkerhill Hotel } \\
\text { Sheraton Walkerhill Hotel }\end{array}$ & $\begin{array}{l}\text { Hypoxic ischemic encephalopathy } \\
\text { Diseases in neonatology }\end{array}$ \\
\hline 1999 & $\begin{array}{l}\text { Spring } \\
\text { Autumn }\end{array}$ & $\begin{array}{l}5.14 \\
10.16\end{array}$ & $\begin{array}{l}\text { Oak Valley Resort } \\
\text { Sheraton Walkerhill Hotel }\end{array}$ & $\begin{array}{l}\text { Neonatal sepsis / Kaoru Ashimine } \\
\text { Recent advances in neonatology } \\
4^{\text {th }} \text { President : Dong Gwan Han }\end{array}$ \\
\hline 2000 & Spring & 5.26 & Marriott Hotel & Neonatal cardiopulmonary resuscitation/Hiroshi Nishida, Reobert Courser \\
\hline 2001 & Spring & 5.26 & Asan Medical Center Seoul & $\begin{array}{l}\text { Neonatal resuscitation program / Akiko Goto, Kwang-sun Lee, YJ Jung, JJ } \\
\text { Yoon, MH Kim, DS Park, EH Kim, JH Kang }\end{array}$ \\
\hline & Autumn & 10.20 & Sheraton Walkerhill Hotel & $\begin{array}{l}\text { Recent advances in neonatology/Barry T Bloom, Gilberto R. Pereira, } \\
\text { Steven A Ringer } \\
5^{\text {th }} \text { President : Soo-Young Pi }\end{array}$ \\
\hline 2002 & Spring & 4.26 & KAL Hotel Seogwipo & $\begin{array}{l}\text { Chronic lung disease/Richard D. Bland, Christian P. Speer, Masanori } \\
\text { Fujimura }\end{array}$ \\
\hline & Autumn & 10.19 & Sheraton Walkerhill Hotel & Heart disease in neonatal period \\
\hline 2003 & $\begin{array}{l}\text { Spring } \\
\text { Autumn }\end{array}$ & 5.23 & Muju Resort & $\begin{array}{l}\text { Respiratory system in neonate:development, physiology and clinical } \\
\text { application }\end{array}$ \\
\hline & & $9.19-20$ & Sheraton Walkerhill Hotel & $\begin{array}{l}\text { Neonatal Lung Group \& Neonatal Brain Group and Others / Hajime } \\
\text { Togari, Petra Hüppy, Colin J Morley, Bo Sun, Christian P. Speer } \\
6^{\text {th }} \text { President : Soo-Ji Moon }\end{array}$ \\
\hline 2004 & $\begin{array}{l}\text { Spring } \\
\text { Autumn }\end{array}$ & $\begin{array}{l}5.21 \\
10.23\end{array}$ & $\begin{array}{l}\text { Hotel Hyundai Gyeongju } \\
\text { Sheraton Walkerhill Hotel }\end{array}$ & $\begin{array}{l}\text { Neonatal respiratory care / Takeshi Horiuchi } \\
\text { Nutrition and GI problems in neonate/Masanor Fujimura, Laurent Ayasse }\end{array}$ \\
\hline 2005 & Autumn & 10.22 & $\begin{array}{l}\text { Chungnam University } \\
\text { Jeongshimhwa International } \\
\text { Cultural Center } \\
\text { Sheraton Walkerhill Hotel }\end{array}$ & $\begin{array}{l}\text { Recent advances in treatment of extremely preterm infants/Hajime Togari } \\
\text { Thermoregulation and endocrinologic problems of neonate } \\
7^{\text {th }} \text { President: Chung Sik Chun }\end{array}$ \\
\hline 2006 & Spring & 5.19 & Ramada Plaza Jeju & $\begin{array}{l}\text { Desirable medical assistance policy in era of low fertility/Masanori Tamura } \\
\text { Recent advances in neonatology }\end{array}$ \\
\hline & Autumn & 10.21 & Sheraton Walkerhill Hotel & \\
\hline 2007 & Spring & 5.25 & Yong Pyong Resort & $\begin{array}{l}\text { Neonatal intensive care in terms of bioethics/Susumu Itoh, Takashi Kusaka, } \\
\text { Kwang-sun Lee, Victor Yu }\end{array}$ \\
\hline & Autumn & 10.20 & Sheraton Walkerhill Hotel & $\begin{array}{l}\text { Evidence based medicine (EBM) in neonatology - ideal therapeutic } \\
\text { strategies } \\
8^{\text {th }} \text { President: Chul Lee }\end{array}$ \\
\hline 2008 & $\begin{array}{l}\text { Spring } \\
\text { Autumn }\end{array}$ & $\begin{array}{l}5.16 \\
10.25\end{array}$ & $\begin{array}{l}\text { Hyatt Regency Hotel Incheon } \\
\text { Sheraton Walkerhill Hotel }\end{array}$ & $\begin{array}{l}\text { Clinical research in neonates/Satoshi Hattori } \\
\text { Neonatal seizure, late preterm infant/Ann R. Stark }\end{array}$ \\
\hline
\end{tabular}


Table 5. List of the Annual Meetings of the Korean Society of Neonatology (1993-2013) (Contiuned)

\begin{tabular}{|c|c|c|c|c|}
\hline Year & Meeting & Date & Location & Topics / Invited Speakers \\
\hline 2009 & $\begin{array}{l}\text { Spring } \\
\text { Autumn }\end{array}$ & $\begin{array}{l}5.15 \\
10.24\end{array}$ & $\begin{array}{l}\text { BEXCO Busan } \\
\text { Sheraton Walkerhill Hotel }\end{array}$ & $\begin{array}{l}\text { Nutrition in neonate/Kazuo Itabashi } \\
\text { Cutting-edge of neonatal research in Korea/William Oh, Betty Vohr } \\
9^{\text {th }} \text { President : Jung-Hwan Choi }\end{array}$ \\
\hline 2010 & $\begin{array}{l}\text { Spring } \\
\text { Autumn }\end{array}$ & $\begin{array}{l}5.14 \\
10.23\end{array}$ & $\begin{array}{l}\text { The Ocean Resort Yeosu } \\
\text { Sheraton Walkerhill Hotel }\end{array}$ & $\begin{array}{l}\text { Pain of the neonate/Masahisa Funato } \\
\text { Renal \& non-renal fluid \& electrolyte problems of the neonate/Masaki Wada }\end{array}$ \\
\hline 2011 & $\begin{array}{l}\text { Spring } \\
\text { Autumn }\end{array}$ & $\begin{array}{l}5.20 \\
10.22\end{array}$ & $\begin{array}{l}\text { Hotel Inter-Burgo } \\
\text { Sheraton Walkerhill Hotel }\end{array}$ & $\begin{array}{l}\text { Neonatal coagulation disorder/Satoshi Kusuda } \\
\text { Bronchopulmonary dysplasia/Alan H Jobe } \\
10^{\text {th }} \text { President : Chong Woo Bae }\end{array}$ \\
\hline 2012 & $\begin{array}{l}\text { Spring } \\
\text { Autumn }\end{array}$ & $\begin{array}{l}5.17 \\
11.16-17\end{array}$ & $\begin{array}{l}\text { Sheraton Walkerhill Hotel } \\
\text { ICC Jeju }\end{array}$ & $\begin{array}{l}\text { Neonatal sepsis/Yuichi Kondo } \\
\text { New therapeutic modalities in neonatal care }\end{array}$ \\
\hline 2013 & Spring & 4.26 & Lotte Resort Buyeo & Korean neonatal network: raze the old to raise the new/Minoru Kubo \\
\hline
\end{tabular}

Abbreviation: RDS, respiratory distress syndrome.

Table 6. Program of the International Congress on Neonatology : Commemorating the $10^{\text {th }}$ Anniversary of the Korean Society of Neonatology

$$
\text { Neonatal Lung Group }
$$

Chairman : Soo-Young Pi

Influence of surfactant phospholipid metabolism in mature lungs by inhaled nitric oxide

Human surfactant protein-A (SP-A) variants:

Bo Sun (Fudan Univ., China)

1. Distribution and frequency of SP-A alleles with racial differences

2. Association between the SP-A gene locus and respiratory distress syndrome in neonates

Surfactant dysfunction in acute respiratory distress syndrome in term neonates

Myung-Ho Oh (Soonchunhyang Univ., Korea)

Chong-Woo Bae (Kyunghee Univ., Korea)

Chairman : Baek-Keun Lim

Pre-and postnatal inflammatory events in BPD

Clinical characteristics and pathogenesis of atypial chronic lung disease of prematurity

Christian P. Speer (Wuerzburg Univ., Germany)

Beyoung Il Kim (Seoul National Univ., Korea)

Chairman : Chung-Sik Chun

An update on neonatal CPAP

Understanding volume guarantee ventilation

Colin J. Morley (Royal Women's Hospital, Australia)

Colin J. Morley (Royal Women's Hospital, Australia)

김병일, 박국인, 박원순, 배종우, 오명호 등 6 명의 국내 연자들이 제1부 “The lung club”, 제2부 “The brain club”으로 나뉘어 성황리 에 성공적으로 개최되었다(Table 6).

대한신생학회지는 1994 년 5 월에 창간호(제 1 권 1호)가 출판된 이후 2013년 Neonatal Medicine으로 학회지 이름과 표지를 바꾸 었고 5 월 현재 제 20 권 2호가 발행되어 우리나라 신생아학 발전에 큰 기여를 하였다. 또한 신생아 집중치료실에서 전공의 및 전임의 들이 환자를 진단하고 치료하는데 도움을 주고자 '신생아 진료지 침서'를 피수영 책임편집자 주도하에 2003년에 초판을, 2008년에 2판을 간행하였으며, 2010년부터 2013년 8월까지 각 병원NICU에
서 수련을 받고 있는 전임의들에게 신생아학의 최신 지견을 알려 주기 위한 '교육 세미나'가 4회에 걸쳐 개최되었다.

또한 1998년 아시아 - 대양주 주산의학회 기간 중 참석한 일본 동경의대의 Nishida 교수 등과 윤종구 회장 등이 회동을 가진 후 '한일 Exchange Program'을 만들기로 하여 1999년 일본 오끼나와 중부병원의 Ashimine가 처음 초청된 이후 현재까지 꾸준히 양국 학회간의 교류가 지속되어 양국의 신생아학의 발달에 큰 역할을 하였다.

2012년 11월 11일에는 대한신생아학회가 주관한 가장 큰 행사인 ‘제1회 이른둥이 희망찾기' 캠페인 주 행사를 서울 삼성동 섬유센 
Table 6. Program of the International Congress on Neonatology : Commemorating the $10^{\text {th }}$ Anniversary of the Korean Society of Neonatology (Contiuned)

\section{Neonatal Brain Group and Others}

Chairman : Soo-Jee Moon

Steroids and the developing brain what have magnetic resonance techniques taught us?

Petra S. Hüppi (Geneva Univ., Switzerland)

In search of strategies for preventing neonatal brain damage as a sequelae of hypoxia-ischemia, bacterial meningitis, or bilirubin encephalopathy

Won-Soon Park (Sungkyungwan Univ., Korea)

Chairman : Chul Lee

Reduction in the incidence of cerebral palsy among preterm infants

Carbon dioxide and regulation of neonatal cerebral blood flow

Hajime Togari (Nagoya City Univ., Japan)

Hajime Togari (Nagoya City Univ., Japan) Chairman : Byoung-Hoon Yoo

Advances in postnatal neuroimaging-relevance to pathogenesis and treatment of brain injury

Petra S. Hüppi (Geneva Univ., Switzerland)

Neural stem cells for cell and gene therapy in hypoxic ischemic brain injury

Kook In Park (Yonsei Univ., Korea)

Application of in vivo MR spectroscopy in neonatology

Ki-Soo Kim (Ulsan Univ., Korea)

Chairman : Jung-Hwan Choi

Postnatally acquired CMV-infections in very immature infants

Christian P. Speer (Wuerzburg Univ., Germany)

Mechanisms and application of head hypothermia in prevention of hypoxic-ischemic brain damage in neonates

Bo Sun (Fudan Univ., China)

Abbreviations: BPD, bronchopulmonary dysplasia; CPAP, continuous positive airway pressure; CMV, cytomegalovirus.

Table 7. Infant Mortality Rate (per 1,000 Live Births) in Each Country (2010)

\begin{tabular}{|c|c|c|c|c|c|c|c|}
\hline & 1998 & 2007 & 2010 & & 2010 & & 2010 \\
\hline Singapore & 7 & 2.3 & 2.7 & Afghanistan & 121.6 & Peru & 21.5 \\
\hline Hong Kong & 7.4 & 2.9 & 2.9 & Somalia & 103.7 & Brazil & 20.5 \\
\hline Japan & 4.8 & 2.8 & 2.2 & Laos & 57.8 & Philippine & 18.8 \\
\hline Sweden & 6.7 & 2.8 & 2.7 & Cambodia & 54.8 & Thailand & 15.9 \\
\hline Denmark & 7.7 & 4.4 & 4.2 & Miyanmar & 47.7 & China & 15.6 \\
\hline France & 8 & 3.4 & 3.4 & India & 46.1 & Arzentina & 10.5 \\
\hline U.K. & 9.5 & 5 & 4.6 & Nepal & 43.1 & Chile & 7.4 \\
\hline Canada & 8.1 & 4.6 & 4.9 & Iran & 41.1 & Taiwan & 4.6 \\
\hline Austrailia & 9.2 & 4.6 & 4.6 & Iraq & 40.3 & & \\
\hline U.S.A. & 10.5 & 6.4 & 6 & Indonesia & 27 & & \\
\hline Korea & 13 & 4 & 3.2 & North Korea & 26.2 & & \\
\hline
\end{tabular}

타에서 성공적으로 개최되었달.

2013년 금년은 대한신생아학회 창립 20주년이 되는 해로서 학

회지인 Neonatal Medicine 8월호에 특집호를 기획하고 있는 등 특

별한 프로그램이 개최될 예정이다.

\section{5. 신생아 집중치료의 발달의 영향 및 효과 ${ }^{9-13)}$}

우리나라는 1970 년대부터 사회경제적 발전 및 의료기술이 발 전하기 시작하면서 신생아 집중치료도 같이 발달함에 따라 영아 사망률(infant mortality rate, IMR)이 1985년에 1,000명 생존아 당 32.5 에서 2010년 3.2로 현저히 감소하여(Table 7) 개발도상국가 
에서 개발국가로의 진입하게 되었음을 알 수 있다. 2010년 WHO 통계자료에 의하면 영아사망률은 1,000 명 생존아 당 일본이 2.2. 스웨 덴과 싱가폴이 2.7 , 홍콩이 2.9 , 프랑스 3.4 로 낮은 것에 비 해, 아프가니스탄이 121.6 , 소말리아가 103.7 , 라오스가 57.8 , 북 한이 26.2로 높아서 그 차이가 현저하였다(Table 7). GNP (gross national product)와 반비례하는 영아사망률은 한 나라의 경제적 발달의 중요한 지표로 사용되고 있다.

우리나라에서의 영아사망률의 감소는 사회경제적 발전 및 의 료기술 발전은 물론 신생아 집중치료의 발달로 영아사망률의 $1 / 2-2 / 3$ 를 차지하는 신생아사망률(neoatal mortality rate, NMR) 의 감소, 즉 저체중출생아(low birth weight infant, LBWI), 극소저 체중출생아(very low birth weight infant, VLBWI), 초극소출생체 중아(extremely low birth weight infant, ELBWI)의 감소에 의한 것 이라고 할 수 있다(Fig. 2, 3). 신생아사망률의 감소는 각 병원에서

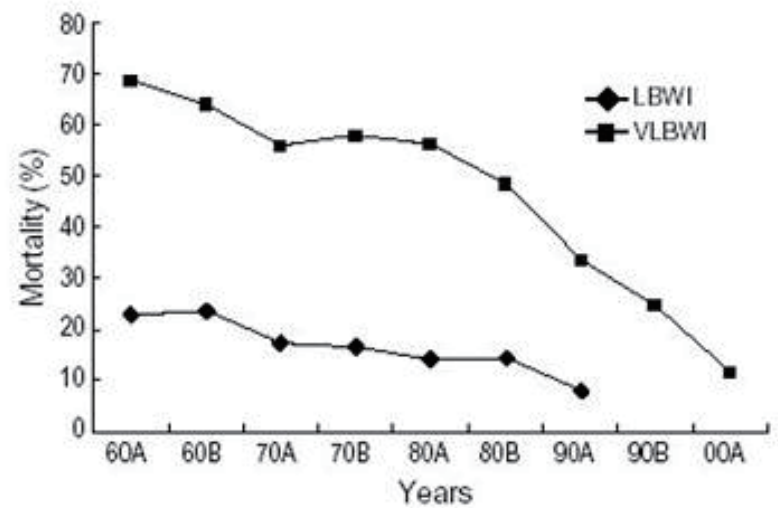

Fig. 2. Changes in the mortality rates (at 5-year intervals during the period 1960-2005) of low birth weight infants (LBWIs) and very low birth weight infant (VLBWIs) in Korea. A, first half of the decade; $\mathrm{B}$, second half of the decade.

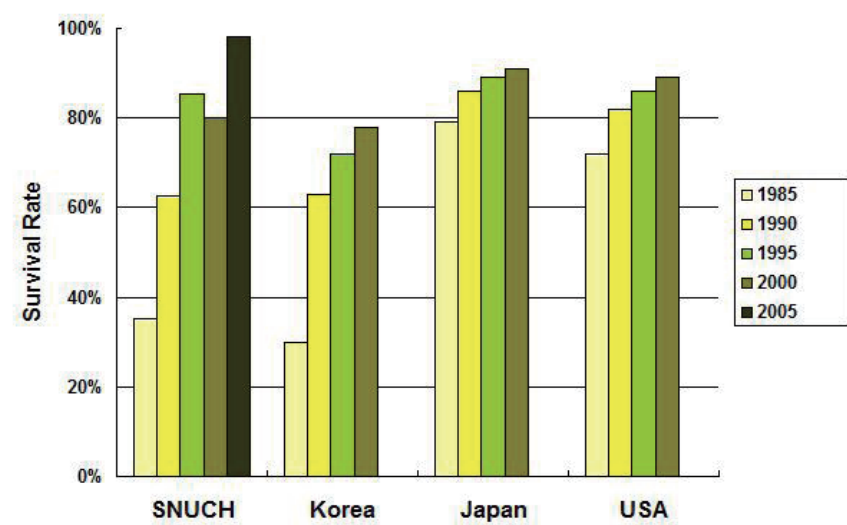

Fig. 3. Comparison of the survival rates among very low birth weight infant (VLBWIs) at Seoul National University Children's Hospital (SNUCH) in Korea and at centers in Japan and the USA (1985-2005).
의 신생아 집중치료의 발달은 물론 대한신생아학회가 큰 역할을 주도했다고 생각된다.

\section{6. 우리나라에서 신생아 집중치료의 발달에 영향을 미친 요인 $24-71$}

우리나라에서 신생아 집중치료의 발달에 영향을 미친 요인들 을 요약해 보면 Table 8에서와 같다. 즉, 첫째, 1970년대부터의 우 리나라 사회경제적 발달 및 의료 기술의 발달에 따른 신생아 집중 치료의 발달, 둘째, 결혼 연령이 증가하고 아이를 적게 가짐에 따 라 태어난 아기를 살리려는 신생아 집중치료에 대한 일반 대중의 요구의 증대, 셋째, 외국에서 우리나라로 초청된 많은 신생아학전 공 학자들에 의한 강의 및 교류를 통한 자극의 증대, 넷째, 우리나 라 신생아학전공 학자들의 외국 유수병원에서의 연수 후 귀국, 다

Table 8. The Influencing Factors for the Development of Neonatal Intensive Care in Korea
1. Socioeconomic \& medical technologic development : facilities, equipment \& manpower
2. Public demand

3. Stimulation by foreign distinguished neonatologists

4. Korean neonatologists : trained at the abroad famous institutes

5. The societies (The Korean Society of Perinatology \& The Korean Society of Neonatology) were established.

6. New hospitals with large scaled neonatal intensive care unit

7. Development of nursing care in neonatal intensive care unit 8. Maternal transport to perinatal center

Table 9. The Present \& Future Problems for the Development of Neonatal Intensive Care in Korea

1. Low number of live births \& crude birth rate

2. Low total fertility rate

- Direct causes

1) Increasing rate of old aged marriage and unmarried women with jobs

2) Small (nuclear) family unit

- Indirect causes

1) Socioeconomic factor

2) Policy of "family planning" : failed

3) High costs on private education

3. Increased LBWI rate

- increased old aged pregnancy

- increased IVF - multiple pregnancy

4. High life span - high old age proportion

5. Low medical fee for the neonatal intensive care

6. A little support from government, city or community

7. No regionalization \& transportation system

Abbreviations: LBWI, low birth weight infant; IVF, in vitro fertilization. 
섯째, 대한주산의학회, 대한신생아학연구회 및 대한신생아학회 의 창립에 의한 학술 교류 장의 확대, 여섯째, 대형 병원의 출현과 함께 대형 신생아 집중치료실의 설립과 기존 대형 병원에서의 신 생아 집중치료실의 확장, 일곱째, 신생아 집중치료실에서의 간호 기술의 발달, 여덟째, 주산기센터로의 산모 이송에 따른 신생아 집중치료의 발달과 산모 및 신생아 생존율 증가 등이 서양보다 늦

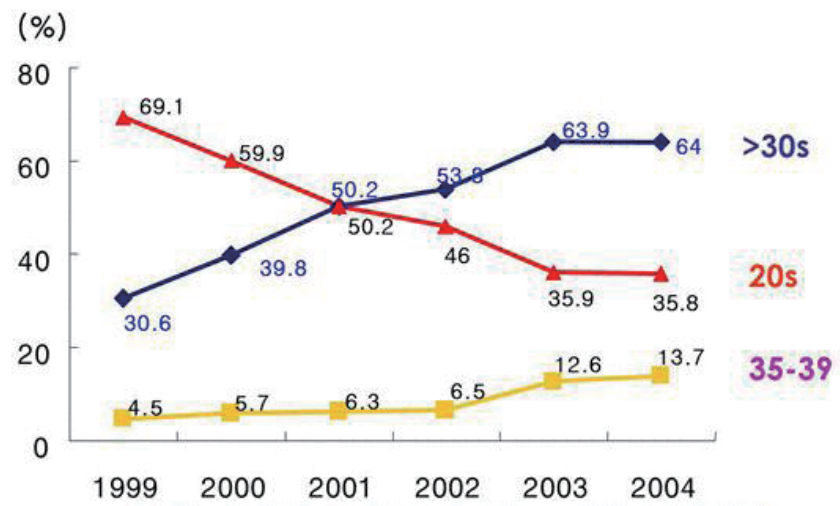

Fig. 4. Annual changes in maternal age at pregnancy in Korea.

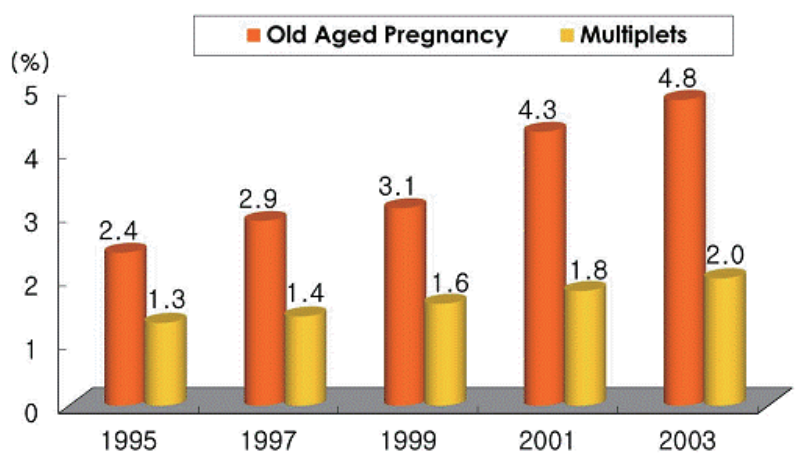

Fig. 5. Correlation between pregnancy at an advanced age and multiple pregnancies and births.
게 시작한 우리나라 신생아 집중치료의 상대적으로 빠른 발달에 기여했다고 할 수 있다.

\section{7. 우리나라에서의 신생아 집중치료의 발달에 따른 현재 및 향 후의 문제점,9-15)}

우리나라에서의 신생아 집중치료의 발달에 따른 현재 및 향후 의 문제점을 요약해 보면 Table 9 에서와 같다. 즉, 첫째, 1 년에 태 어나는 출생 생존아수가 1970년에 100만 명에서 2010년 47만 명 으로 감소 및 낮은 조출생률(crude birth rate; 1970년 31.2, 2010 년 9.4), 둘째, 낮은 합계출산율(total fertility rate; 1970년 4.53, 2010년 1.23)인데, 그 원인 중 직접적 원인으로는 늦게 결혼하거 나 일 때문에 결혼하지 않은 여성의 증가와 핵가족의 증가와 간 접적 원인으로는 사회경제적 요인, '가족계획 정책'의 실패(Table 10), 그리고 사교육비의 증가이며, 셋째로 늦은 나이에 출산하는 여성의 증가와 시험관수정(in vitro fertilization, IVF)에 의한 쌍생 아 임신의 증가로 인한 저출생체중아(LBWI)의 증가(Fig. 4,5$)$, 넷 째, 높은 수명과 고령인구의 증가, 다섯째, 신생아 집중치료에 대 한 낮은 의료수가, 여섯째, 정부, 시 또는 지방자치단체로부터의 적은 지원, 일곱째, 아직 지역화 및 이송 체계(regionalization \& transportation)가 정립되어 있지 않은 것 등이라고 할 수 있다.

\section{결론}

서양과 비교하여 우리나라의 신생아 집중치료가 어떻게 발달 되어 왔는지를 돌아보고 우리나라에서의 현재 및 향후의 문제점 들을 알아본 결과 다음과 같은 해결방안을 제시하고자 한다 ${ }^{2,4-6,11}$ (Table 11).

즉, 첫째, 전국적인 통계자료(vital statistics)를 위한 체계적인 데이타 수집을 포함한 신생아 집중치료를 하기 위한 잘 조직된 주

Table 10. 'Changes of Slogan' on Family Plan in Korea

\begin{tabular}{ll}
\hline 1960 s & Having a baby without a plan will lead to become a "beggar" \\
Early 70 & Whether the baby is a boy or a girl, have only two children and bring them up well \\
Late 70 & One well grown-up daughter is more enviable than ten sons \\
2004 & Daddy, I hate being alone. Mommy, I really want to have many brothers/sisters
\end{tabular}

Table 11. The Future Solution for the Development of Neonatal Intensive Care in Korea

1. Set-up the Organizing Perinatal Center for managing the neonatal intensive care, including nationwide systematic data collection system for vital statistics

2. Set-up the support system for neonatal intensive care : financial \& social support for facilities, equipment \& man power, and its maintenance from government, city, or community

3. Rational reformation of the medical fee of neonatal intensive care

4. Set-up regionalization and transportation system 
산기 센터의 설립, 둘째, 신생아 집중치료에 대한 재정적, 사회 적 지지체계(시설, 장비와 인적 파워의 유지를 위한 정부, 시, 지 방자치단체로부터)의 확립, 셋째, 신생아 집중치료에 대한 합리 적 의료수가의 개혁, 넷째, 지역화 및 이송 체계(regionalization \& transportation system) 확립 등인데 2013년에 설립되어 출범한 한 국 신생아 네트워크로 많은 문제들이 해결될 것으로 기대되며, 저 출산에 대한 정책으로 정부, 시, 지방자치단체 등으로 부터의 지 원도 점차 늘어가고 있어 향후 우리나라 신생아 집중치료의 발달 은 고무적이라 할 수 있다고 생각된다.

\section{REFERENCES}

1) Avery GB. Neonatology: past, present and future. In: McDonald MG, Mullett MD, Seshia MMK, Avery's neonatology. 6th ed. Philadelphia: Lippincott Williams \& Wilkins, 2005;3-7.

2) Choi JH. The historical overview of the neonatal intensive care. The Seoul Neonatology Symposium; 2007 May 23; Seoul. Seoul: Seoul National University Children's Hospital, 2007.

3) Sumner JY. Lawrenece MG, Carol BG, Louis G, Joseph LB. Neonatal intensive care; a history of excellence. A Symposium Commemorating Child Health Day; 1992 Oct; Bethesda. Maryland: National Institutes of Health, 1992.

4) Shin SM. Current status and a prospect of neonatal intensive care units in Korea. J Korean Med Assoc 2006;49:983-9.

5) Shin SM. Current status of neonatal intensive care units in Korea. Korean J Pediatr 2008;51:243-7.

6) The Korean Society of Neonatology. Introduction of the KSN.
Available from: URL: http://neonatology.or.kr/about/history_ foundation.html/.

7) The Korean Society of Perinatology. Introduction of the KSP. Available from: URL: http://perinatol.or.kr/html/info03.asp/.

8) Kim CR, Bae CW. The significance of the first campaign of "Prematuriy, Hope". Neonatal Med 2013;20:20-7.

9) Statistics Korea, Korean Statistical Information Service. Annual Report on the vital statistics [Internet]. Daejeon: Statistics Korea; C1996. [cited 2013 Aug 1] Available from: http://www.kosis.kr/.

10) WHO. Health statistics and health information systems, infant mortality [cited 2013 Aug 1]. Available from: http://www.who. int/healthinfo/mortables/en/index.html.

11) Bae CW. Neonatal epidemiology in Korea: statistics and clinical data. 1st ed. Seoul: Shinheung MedScience Inc, 2012: 14-221.

12) Kim DH, Shim SY, Kim JR, Shin SH, Kim ES, Jung KE, et al. Recent outcome of extremely low birth weight infants: The use of CRIB(clinical risk index for babies) II score for analyzing the survival. Korean J Pediatr 2006;49:952-8.

13) Lim JW. The changing trends in live birth statistics in Korea, 1970-2010. Korean J Pediatr 2011;54:429-35.

14) Moon JY, Hahn WH, Shim KS, Chang JY, Bae CW. Changes of maternal age distribution in live brths and incidence of low birth weight infants in advanced maternal age group in Korea. Korean J Perinatol 2011;22:30-6.

15) Choi SH, ParkYS, Shim KS, Choi YS, Chang JY, Hahn WH, et al. Recent trends in the incidence of multiple births and the consequences on perinatal problems in Korea. J Korean Med Sci 2010;25:1191-6. 